\title{
A simple incubation tank for photosynthesis measurements with six light intensities
}

\author{
Viktor R. Tóth* and Sándor Herodek \\ Hungarian Academy of Sciences, Balaton Limnological Research Institute, Klebelsberg K.u. 3, Tihany, 8237, Hungary
}

Received 30 January 2009; Accepted 7 July 2009

\begin{abstract}
The aim of the study was to design and put together a compact, easy-to-assemble and costefficient incubation system for aquatic plant photosynthesis measurements. Incubation tank consisting of glass sidewalls and mirror inner walls was constructed. The tank was split into six incubation cells and two water collecting cells. Each incubation cell was built of mirror with reflective side turned into the incubation cells to prevent the self shading of plants and minimized the variance of light intensity within the cell. The wall of each incubation cell facing the source of light was made of $3 \mathrm{~mm}$ glass and was covered by light absorbing film. To produce different light intensities single light source (fluorescent tubes) and light absorbing film (3M Scotchtint ${ }^{\mathrm{TM}}$ Sun Control RE50NEARL) were chosen. The sidewall of each incubation cell was covered with metal-coated neutral sun control film to produce six distinct light intensities. The different transparency of the sidewalls was achieved by lamination of the chosen film in increasing numbers of layers. The effect of the lamination on optical properties of the film was also studied. The variation of photon flux density within a cell was $3.9 \%$. Continuous use of the system and occasional repetitive measurements of film's transparency showed that it maintained its neutral optical properties over a long period of time.
\end{abstract}

Key words: Incubation tank / photosynthesis / light intensities / aquatic macrophytes / ecophysiology

\section{Introduction}

Irradiance in aquatic environment shows great temporal, spatial and spectral variation (Sand-Jensen, 1989; Björkman and Demmig-Adams, 1994; Kirk, 1996; Wetzel, 2001). Besides the atmospheric attenuation of solar radiation, light in the water column is altered by additional factors like air/water surface reflection, back-scattering, absorption by water and suspended particles, shading effect of aquatic macrophytes and epiphytes (Sand-Jensen, 1989; Kirk, 1996; Van Duin et al., 2001). The great deviation in photon flux density in aquatic environment demands a photosynthetic apparatus with equally great responsiveness.

Photosynthesis is one of the most studied processes of macrophyte physiology (for example: Maberly, 1983; Sand-Jensen and Madsen, 1991; Schwarz and HowardWilliams, 1993; etc.). The sensitivity of photosynthesis to a large amount of abiotic (Adams et al., 1974; Madsen and Sand-Jensen, 1991; Madsen et al., 1996; Short and Neckles, 1999) and biotic factors (Sand-Jensen, 1977;

\footnotetext{
*Corresponding author: donvito@tres.blki.hu
}

Kirk, 1996; Larcher, 2003) makes it a perfect tool for stress physiological researches, as an indicator process in test studies and environmental risk assessments, etc. (Wang and Freemark, 1995; Nyström et al., 2002; Lambert et al., 2006). The only limitation that stops the spread and usage of plants photosynthesis processes for test procedures is the price and the complexity of equipments used for photosynthesis measurements.

A great variety of non-destructive method of photosynthesis measurements is known. In studies of recent years mostly chlorophyll fluorescence was used for estimation of photosynthetic capacity of a plant (Nyström et al., 2002; Eggert et al., 2003; Cedergreen et al., 2005; Lambert et al., 2006; Shen and Song, 2007). Besides chlorophyll fluorescence oxygen consumption and carbon emission can be utilised in experiments via direct measurement with different types of electrodes (Vermaat and Verhagen, 1996; Maberly and Madsen, 1998; Asaeda et al., 2004; Jones, 2005; Shen and Song, 2007; Machova et al., 2008). A number of experiments used special equipments that employ either the $\mathrm{O}_{2}$ consumption (Kamara and Pflugmacher, 2007 and references) or the $\mathrm{CO}_{2}$ emission of the photosynthesis (Silva et al., 2005). 
All the above mentioned equipments are factory-built, but substantially could be easily replaced by a cheaper and still effective apparatus made by the scientist itself.

The rate of photosynthesis is mostly affected by irradiance (Adams et al., 1974; Madsen and Sand-Jensen, 1991), therefore the most important part of the equipment should be the careful planed light sources. To record the light curve of photosynthesis (photosynthetic response to varying light intensities) a number of light intensities is needed. To produce discrete light intensities for photosynthesis study two alternative ways are possible. The first possibility is the use of multiple artificial light sources to produce each light intensity individually by changing the intensity of the emitted light. Alternatively, there is a possibility of use of a single light source. Different light intensities would be produced by attenuating irradiance of this light source. The former solution can result a spectrally diverse set of light sources and led to deceptive readings of photosynthesis, while the latter produce spectrally identical sources, that differ only in the intensity of light.

In this study we describe a compact, easy-to-assemble and cost-efficient incubation system for measuring aquatic plant photosynthesis. Using this system it is possible to measure the light response curves with six discrete light intensities (and in the dark) on multiple aquatic organisms at the same time. The temperature and the light gradient of the incubation system could be easily modified, which makes the equipment more exploitable.

\section{Materials and methods}

In the experiments as source of light metal-halide (A5, Tungsram, Hungary, correlated colour temperature$4500 \mathrm{~K}$ ) and fluorescent (F33 Coolwhite, Tungsram, Hungary, correlated colour temperature $4000 \mathrm{~K}$ ) lamps were used.

For attenuation of emitted light Scotchtint ${ }^{\mathrm{TM}}$ Sun Control and Scotchshield ${ }^{\mathrm{TM}}$ Ultra Safety and Security Window films (3M, USA) were used. Spectral profile of films was assessed with a spectrophotometer (UV-1601, Shimadzu, Japan).

Spatial distribution of irradiance within the incubation tank was measured with a spherical irradiance meter US-SQS/L sensor (WALZ, Germany) and the data were collected by a LI-COR LI 1400 data logger (LI-COR Biosciences $\mathrm{GmbH}$, Germany).

The control of temperature was maintained by a cooling-heating bath (Neslab RTE-17, Thermo Electron, USA). The temperature within the incubation tank, and each incubation cell was recorded with digital thermometer (Testo mini 525, Testo, UK).

For testing the incubation system on submerged macrophytes Potamogeton perfoliatus L., Myriophyllum spicatum L., Najas marina L. and Ceratophyllum demersum $L$. were used. Substrate attached intact plants were collected by hand in the surroundings of the Balaton Limnological Research Institute (46 $54^{\prime} 46.54^{\prime \prime} \mathrm{N}, 17^{\circ} 53^{\prime}$
37.53" E) in the best possible condition. At arrival to laboratory no pre-incubation was performed. The $3 \mathrm{rd}$ and 4th youngest fully grown leaves (branches of $N$. marina) were detached, thoroughly washed and placed into a Karlsruhe vials, filled with filtered (pore size $0.45 \mu \mathrm{m}$ ) and aerated (95\% saturation) lake water. Water filled vials were transferred into the incubator and the temperature of the cooling heating bath was set to actual water temperature of lake Balaton. Mixing was provided by stirring bars and specially made magnetic stirrers (rotation speed$30 \mathrm{rpm}$ ) placed under the incubation tank. Photosynthesis was measured using oxygen electrode (TriOxmatic 300, WTW, Germany) connected to a data logger (Oxi 539 microprocessor precision oxygen meter, WTW, Germany).

\section{Results and discussion}

\section{Incubation tank}

The incubation tank was designed to fit $6,235 \mathrm{~mm}$ long, $80 \mathrm{~mm}$ wide and $110 \mathrm{~mm}$ deep incubation cells (Fig. 1 labelled from A to F) and two water collecting cells ( $80 \mathrm{~mm}$ long and $165 \mathrm{~mm}$ wide, Fig. $1, \alpha$ and $\beta$ ). Each incubation cell was considered to take three Karlsruhe vials, while the water collecting cells were planed to simplify the inlet and outlet of water and the regulation of water level within the incubation tank. The inner sidewalls of incubation cells (Fig. 1, solid lines) were made of $3 \mathrm{~mm}$ mirror glass with reflective side facing inside each incubation cell. The 4th wall (Fig. 1, dotted line) facing the light source was made of a $3 \mathrm{~mm}$ glass. The incubation tank was glued onto the reflective side of $6 \mathrm{~mm}$ thick $(950 \times 180 \mathrm{~mm})$ mirror glass base. The neighbouring incubation cells within rows A-B-C and D-E-F were separated by a $6 \mathrm{~mm}$ gap. Each short $(80 \mathrm{~mm})$ wall of the incubation cells had a hole and the walls were arranged so that light from the adjacent cells could not get through, but the water would pass through the hole, to the gaps and into the neighbouring cell easily (Fig. 1).

\section{Light source}

Metal-halide and fluorescent lamps were used as light sources. A metal-halide lamp produced sufficient amount of light $\left(2000-2500 \mu \mathrm{mol} \cdot \mathrm{m}^{-2} \cdot \mathrm{s}^{-1}\right)$, with optical properties similar to irradiance of the Sun, but with excessive radiation of heat. Illumination of a single incubation cell for $30 \mathrm{~min}$ from distance of $10 \mathrm{~cm}$ without cooling increased the temperature within the cell from $23.0 \pm 0.0$ to $47.7 \pm 1.5{ }^{\circ} \mathrm{C}$. In contrast, a fluorescent tube produces only a fraction of natural light's irradiance (200$250 \mu \mathrm{mol} \cdot \mathrm{m}^{-2} \cdot \mathrm{s}^{-1}$ ) with spectral properties that differ from those of the Sun, but since it uses non-thermal radiation processes to produce light, the amount of emitted heat is not significant. The temperature in a single incubation cell after $30 \mathrm{~min}$ of illumination with fluorescent 


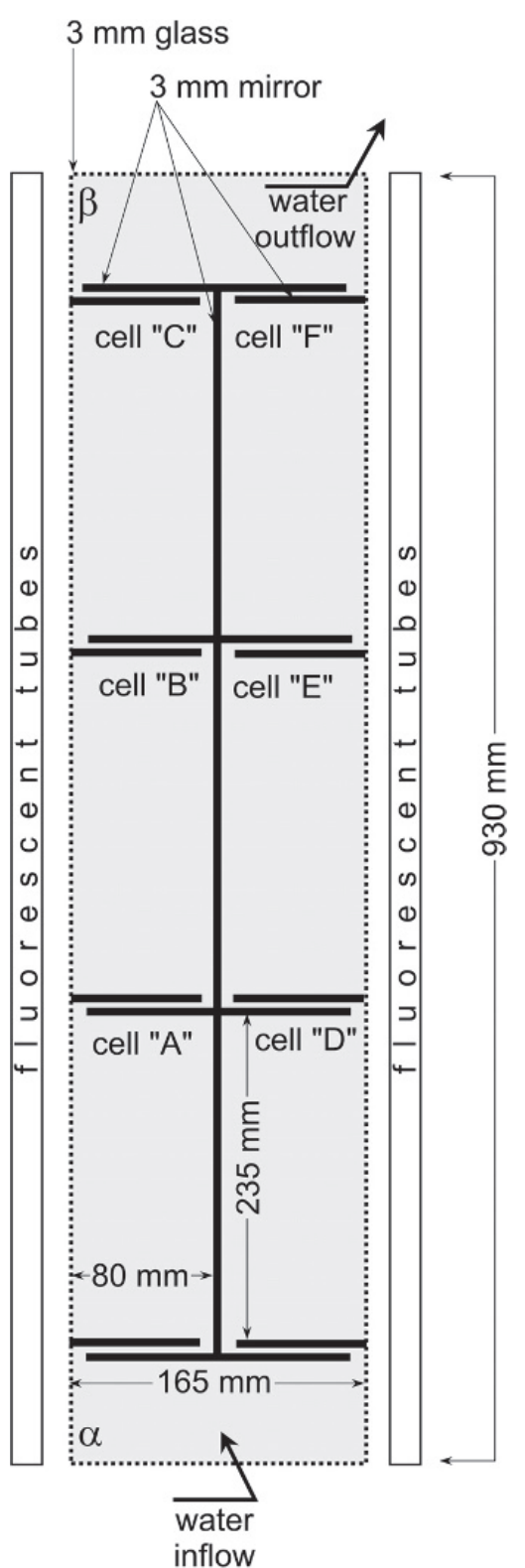

Fig. 1. Top view of the incubation tank showing six incubation (from $\mathrm{A}$ to $\mathrm{F}$ ) and two collecting cells ( $\alpha$ and $\beta$ ). The inner sidewalls of each incubation cell were made of $3 \mathrm{~mm}$ mirror glass (bold lines) placed with reflective side in. The sidewalls of the incubation tank were made of $3 \mathrm{~mm}$ glass (dash line). The whole structure mounted on a $6 \mathrm{~mm}$ mirror glass base with reflective side up.

lamp from a distance of $10 \mathrm{~cm}$ without cooling increased by $5.4 \pm 0.6{ }^{\circ} \mathrm{C}$. To achieve the necessary maximal irradiance for the photosynthesis measurements five $36 \mathrm{~W}$ fluorescent lamps were arranged on a very short distance parallel to each other. As a result of this arrangement maximal light intensity of $1200 \mu \mathrm{mol} \cdot \mathrm{m}^{-2} \cdot \mathrm{s}^{-1}$ was reached. In our experiments F33 Coolwhite fluorescent lamps were used due to their relatively uniform radiation in the photosynthetically active radiation (PAR) range (only two significant energy peaks in the spectral power distribution).
To test the thermal capacity of the system we placed 18 Karlsruhe vials (three in each incubation cell) into the incubation tank. The vials and the incubation tank were filled with distilled water. The incubation cells closest to water inflow from the bath were the cell $\mathrm{A}$ and $\mathrm{D}$, while the farthest were $\mathrm{C}$ and $\mathrm{F}$ (Fig. 1). The cooling-heating bath was set to room temperature $\left(2{ }^{\circ} \mathrm{C}\right)$. The temperatures in the Karlsruhe vials were recorded with digital thermometer.

At full water flow of the bath $\left(15 \mathrm{~L} \cdot \mathrm{min}^{-1}\right)$ the fluorescent lamps didn't increased the temperature significantly. At the end of one hour illumination period the difference between the temperature of the cell " $\mathrm{A}$ " and cell " $\mathrm{C}$ " was $0.2 \pm 0.1{ }^{\circ} \mathrm{C}$ ( $t$-test, $\left.t=-0.71, P=0.52\right)$. Contrary, metal-halide lamps increased the temperature significantly, since cell "C" was $1.7 \pm 0.4{ }^{\circ} \mathrm{C}(t$-test, $t=-3.78, P=0.02)$ warmer than incubation cell " $\mathrm{A}$ ". The rest of experiments were performed using fluorescent lamps.

\section{Attenuation of light}

As light absorbing material three types of Scotchtint ${ }^{\mathrm{TM}}$ Sun Control films (NEARL types: medium neutral, light neutral and very light neutral) and four types of Scotchshield $^{\mathrm{TM}}$ Ultra Safety and Security Window films (NEAR400 types: very high performance neutral, high performance neutral, medium neutral and light neutral) (3M, USA) were used. Each film was glued to a $10 \mathrm{~mm} \times 50 \mathrm{~mm}$ piece of $3 \mathrm{~mm}$ glass. Twenty-four hours for drying were allowed. The spectral profile of the glass attached films was tested on a spectrophotometer.

The majority of tested films (5 out of 7) showed fluctuating spectral profile of light transmittance (Fig. 2). The transmittance curves of all Scotchshield NEAR400 type films showed significant (14-24\%) decrease at red (i.e. $650-700 \mathrm{~nm})$, green $(520-570 \mathrm{~nm})$ and blue $(440-$ $450 \mathrm{~nm}$ ) wavelengths (Fig. 2A). The coefficients of variation $\left(\mathrm{C}_{\mathrm{V}}\right)$ of transmittance of these films were between 0.2 and 1.3, while the glass and the Scotchtint ${ }^{\mathrm{TM}}$ RE50NEARL and RE70NEARL films had more stable spectral profile, with relatively low variance $\left(\mathrm{C}_{\mathrm{V}}<0.05\right)$. The RE50NEARL and RE70NEARL films cut off 53 and $55 \%$ of the incident light (Fig. 2B), thus due its lower transmittance $3 \mathrm{M}$ Scotchtint ${ }^{\mathrm{TM}}$ Sun Control RE50NEARL film was used in further experiments.

Effect of layering on the spectral properties of the film was also tested by measuring the transparency of a test glass $(10 \mathrm{~mm} \times 50 \mathrm{~mm}$ pieces of $3 \mathrm{~mm}$ glass $)$ with varying number of attached $3 \mathrm{M}$ Scotchtint ${ }^{\mathrm{TM}}$ Sun Control RE50NEARL films. In the set we compared the spectral profile of transparency of a not coated piece of glass, with five film coated pieces of test glass. Each film coated glass had a different number of layers (from 1 to 5) stratified. Spectral profiles were recorded with a spectrophotometer. Each added layer of $3 \mathrm{M}$ Scotchtint ${ }^{\mathrm{TM}}$ Sun Control RE50NEARL film decreased the transparency proportionally $(-52 \pm 6 \%)$ nearly all through the PAR spectra (Fig. 3). The only significant deviation was 


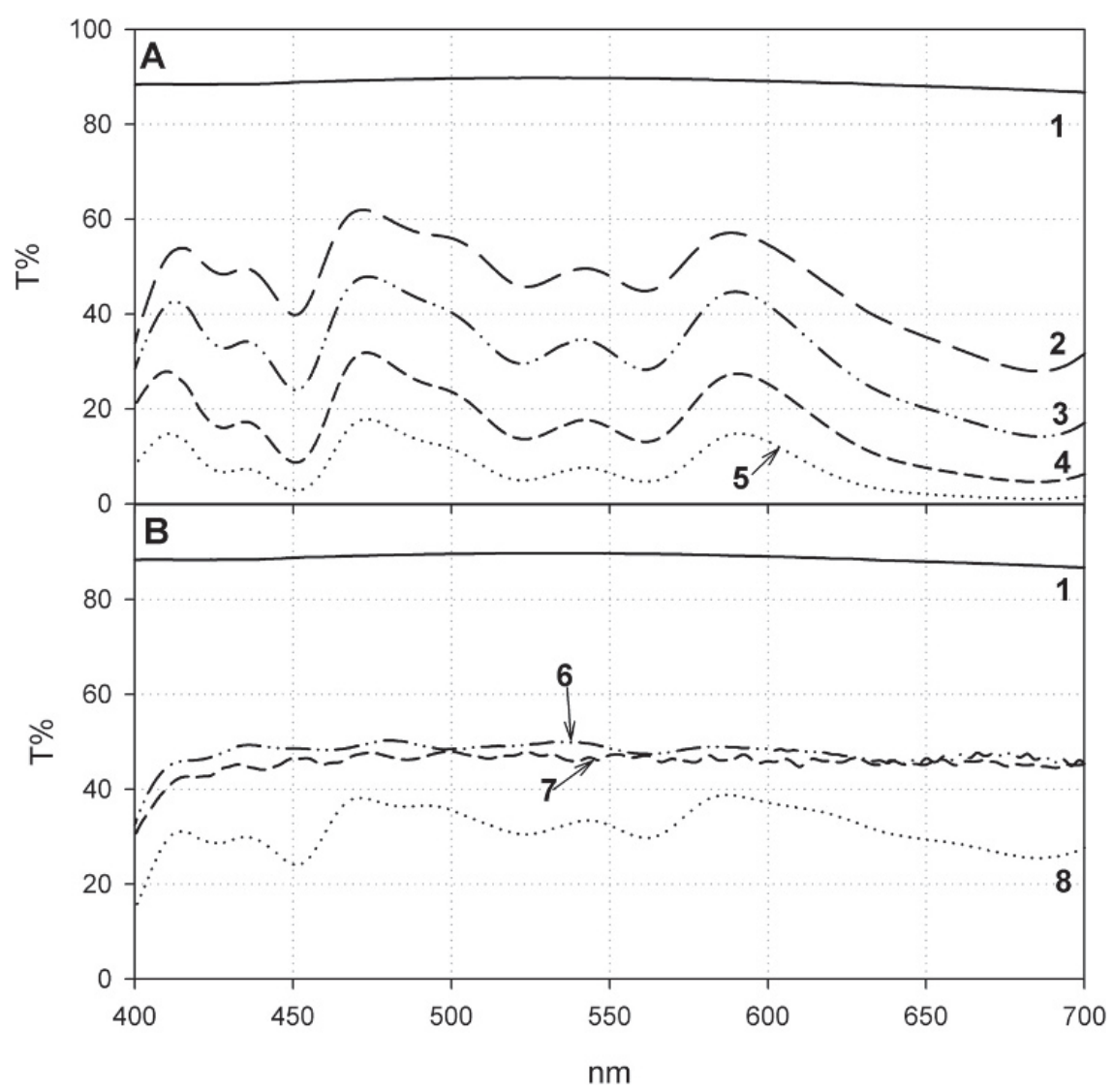

Fig. 2. The spectral profile of light transmittance in $3 \mathrm{~mm}$ glass and different neutral sun control films attached to $3 \mathrm{~mm}$ glass. Transmittance of Scotchshield ${ }^{\mathrm{TM}}$ Ultra Safety and Security Window (NEAR400) and Scotchtint ${ }^{\mathrm{TM}}$ Sun Control (NEARL) films. 1 - 3 mm glass, 2 - S50NEAR400, 3 - S35NEAR400, 4 - S20NEAR400, 5 - S5NEAR400, 6 - RE70NEARL, 7 - RE50NEARL and 8 - RE35NEARL films on $3 \mathrm{~mm}$ glasses.

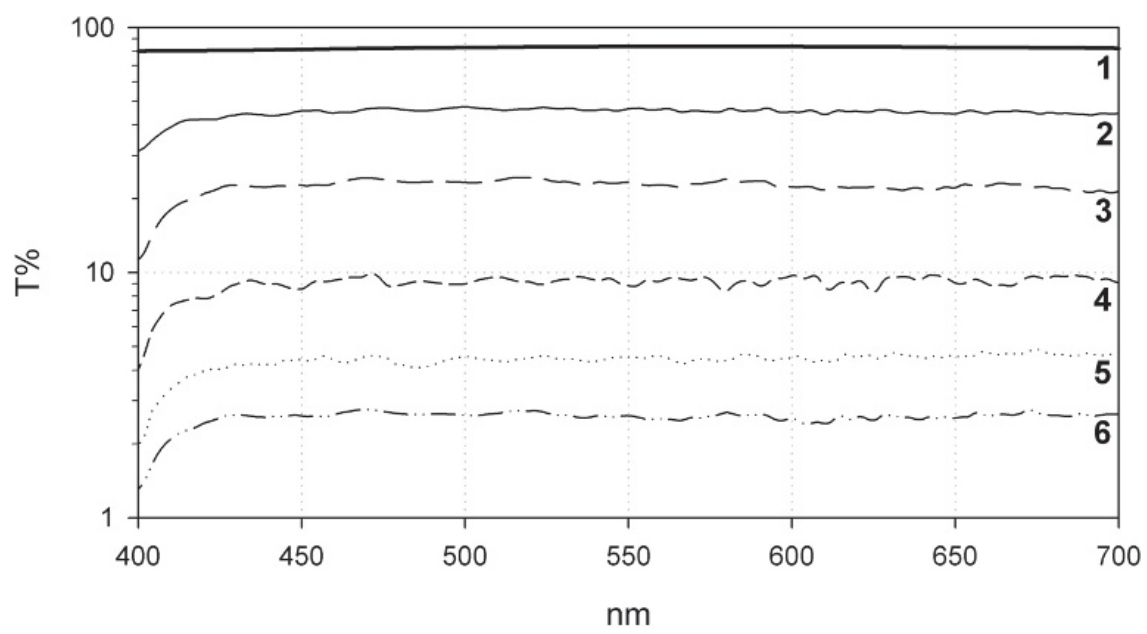

Fig. 3. Transmittance of $3 \mathrm{~mm}$ glass and of varying number of layers of Scotchtint ${ }^{\mathrm{TM}}$ RE50NEARL type Sun Control film attached to a $3 \mathrm{~mm}$ glass. $\mathbf{1}-3 \mathrm{~mm}$ glass, $\mathbf{2}-1$ layer, $\mathbf{3}-2$ layers, $\mathbf{4}-3$ layers, $5-4$ layers and $\mathbf{6}-5$ layers of film on $3 \mathrm{~mm}$ glass.

detected in the blue end spectra of PAR (400-414 nm) where additional transparency decrease was observed $(34 \pm 6 \%)$ (Fig. 3).

The tested $3 \mathrm{M}$ Scotchtint ${ }^{\mathrm{TM}}$ Sun Control RE50NEARL films were applied to the transparent sidewall of incubation cells. The sidewall of the incubation cell "A" was not covered with sun control film, while the sidewalls of the other five incubation cells ("B" to " $F$ ", Fig. 1) were coated with one (cell "B") to five (cell "F") layers of 3M Scotchtint ${ }^{\mathrm{TM}}$ Sun Control RE50NEARL film. 


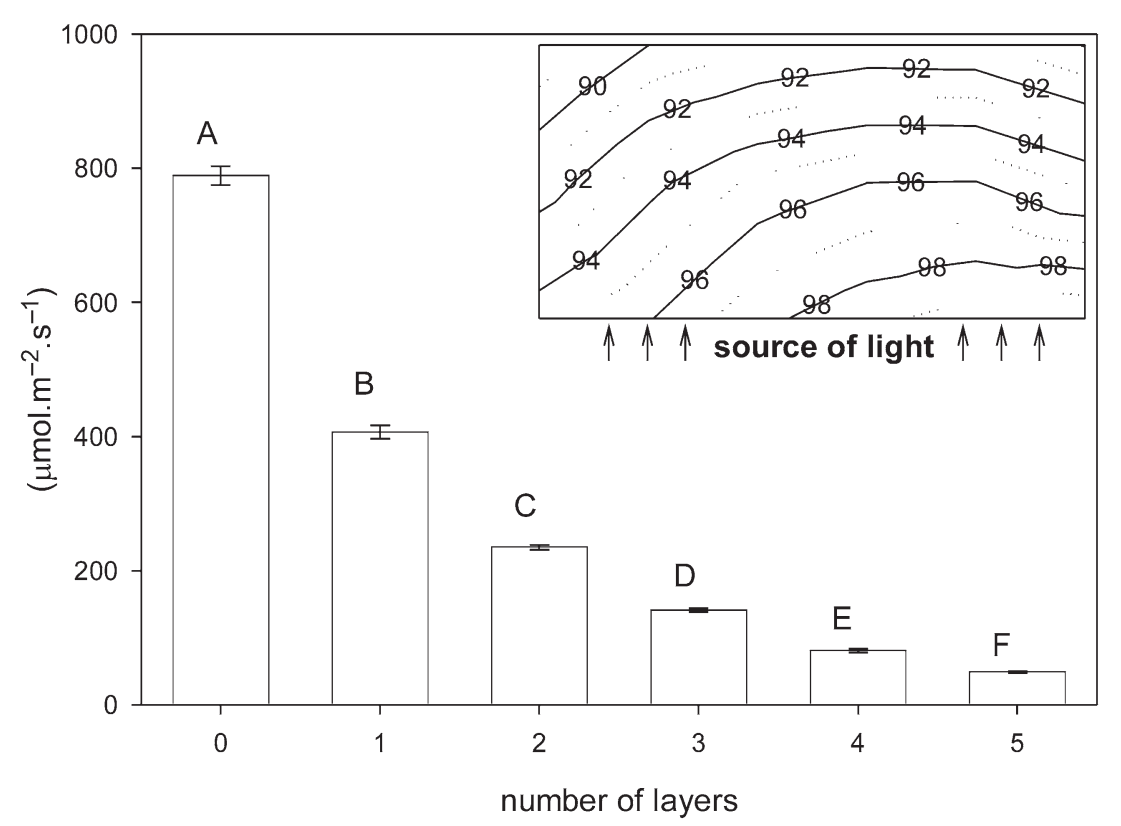

Fig. 4. Effect of different number of layers of Scotchtint ${ }^{\mathrm{TM}}$ RE50NEARL type Sun Control film on light intensity within Karlsruhe vials placed into incubation cell. Each column represents mean \pm SD of nine measurements. Inlay: Average spatial distribution of irradiance within the incubation cells covered with varying number of layers of Scotchtint ${ }^{\mathrm{TM}}$ RE50NEARL type Sun Control film.

Thus, incubation tank had one cell with no film on its sidewall and five cells with one to five films layered upon the transparent sidewalls of the incubation cells (dotted line of each incubation cell, Fig. 1).

As light source, five $36 \mathrm{~W}$ fluorescent lamps placed $15 \mathrm{~cm}$ from the sidewalls (dotted line, Fig. 1) of the incubation cells were used. The average light intensity within the incubation cell not covered with film was $784 \pm$ $28 \mu \mathrm{mol} \cdot \mathrm{m}^{-2} \cdot \mathrm{s}^{-1}$ (Fig. 4). Each added layer of sun control film decreased the irradiance by $42.5 \pm 3.5 \%$ (Fig. 4), consequently the average light intensity in the cell " $F$ " covered with five layers of RE50NEARL film was $49 \pm$ $2 \mu \mathrm{mol} \cdot \mathrm{m}^{-2} \cdot \mathrm{s}^{-1}$.

The spatial distribution of light within the incubation cells was studied (Fig. 4, inlay). The incubation tank was filled with distilled water and the light intensity within each cell was recorded at 18 points at the same height (middle of the incubation cell $-5.5 \mathrm{~cm}$ from the base) following a fixed spatial pattern. Due to the mirror glass walls, the variations of irradiance within the cells were relatively low and stayed within the range of $3.9 \pm 0.3 \%$ (Fig. 4, inlay).

Variance of light intensity within Karlsruhe vials was also determined. Water filled Karlsruhe vials were placed within water filled incubation cells and the irradiance was measured at three different heights at each vial with spherical light sensor. The light intensity within the Karlsruhe vials exponentially decreased from $782 \pm$ $14 \mu \mathrm{mol} \cdot \mathrm{m}^{-2} \cdot \mathrm{s}^{-1}$ in the cell "A" to $49 \pm 1 \mu \mathrm{mol} \cdot \mathrm{m}^{-2} \cdot \mathrm{s}^{-1}$ in the cell " $F$ ". The variance of light intensity within the vials was $2.1 \pm 0.5 \%$.

Durability of spectral properties were tested by exposing pieces of test glasses of $3 \mathrm{M}$ Scotchtint ${ }^{\mathrm{TM}}$ Sun Control RE50NEARL film used in the experiments depicted in Figure 3 illuminating by the light of the sun (maximum light intensity $2110 \mu \mathrm{mol} \cdot \mathrm{m}^{-2} \cdot \mathrm{s}^{-1}$ ) for a longer time (five months - April to October). No significant changes in the spectral resolution and rate of light cut-off were observed, suggesting the adequacy of the chosen film for similar devices.

\section{Incubation system}

Temperature stability of the incubation system was also tested. Karlsruhe vials filled with water and leaves of a macrophyte (Potamogeton perfoliatus L.) were placed into the water filled incubation tank. The tank was illuminated from both sides with five $36 \mathrm{~W}$ fluorescent lamps placed $15 \mathrm{~cm}$ from the incubation tank's wall. The temperature of the cooling-heating bath was set to $20{ }^{\circ} \mathrm{C}$ and the circulation of the bath was set to maximum $\left(15 \mathrm{~L} \cdot \mathrm{min}^{-1}\right)$. The light was switched on for six hours and the temperatures within Karlsruhe vials were recorded every hour with a digital thermometer. Figure 5 shows the results of the test performed on the most illuminated side (i.e. covered with less layers of RE50NEARL film, cells "A", "B", "C", Fig. 1) of the incubation tank. The majority of temperature changes occurred within an hour after the light of the incubation system was switched on. In cell " $A$ " (closest to the water inflow) after one hour of illumination there was no measurable temperature change, while in cell "B" and cell "C" (closest to the water outflow) the water temperatures within the Karlsruhe vials increased by $0.10 \pm 0.00$ and $0.20 \pm 0.06{ }^{\circ} \mathrm{C}$, respectively (Fig. 5). After six hours of illumination the temperatures in cells " $\mathrm{A}$ ", "B" and "C" were 23.07 $\pm 0.03,23.17 \pm 0.03$ and 23.27 \pm $0.03{ }^{\circ} \mathrm{C}$ respectively (Fig. 5). On average the temperature increase at $20{ }^{\circ} \mathrm{C}$ was $0.16 \pm 0.03{ }^{\circ} \mathrm{C}$. The temperature 


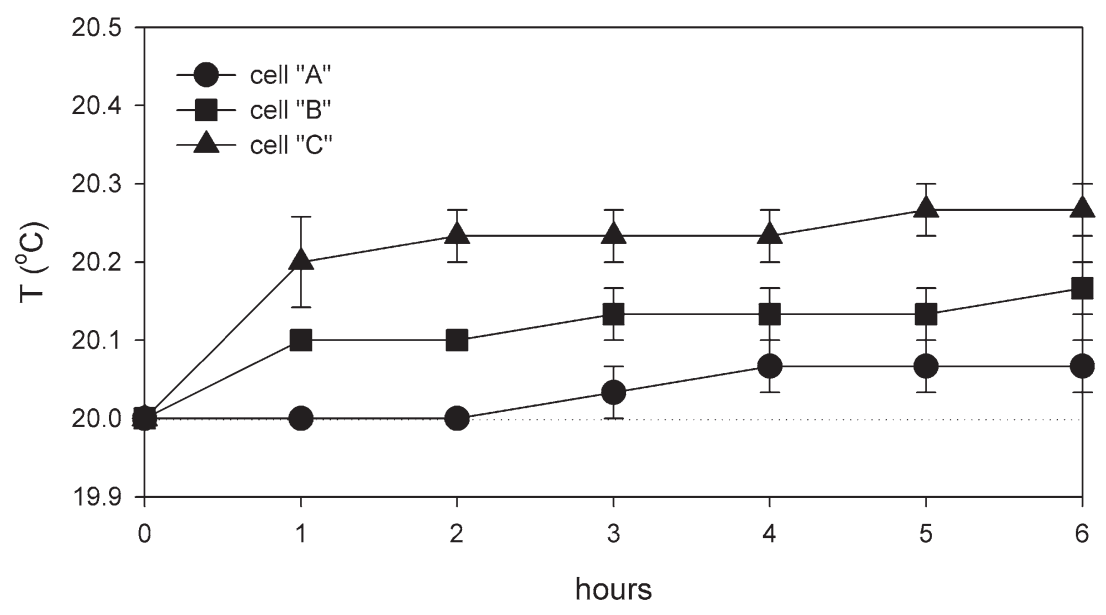

Fig. 5. Change of temperature within Karlsruhe vials in the most illuminated incubations cells (cells "A", "B" and "C") during six hours of constant exposure to the light of fluorescent tubes. Each symbol represents mean \pm SD of three measurements.

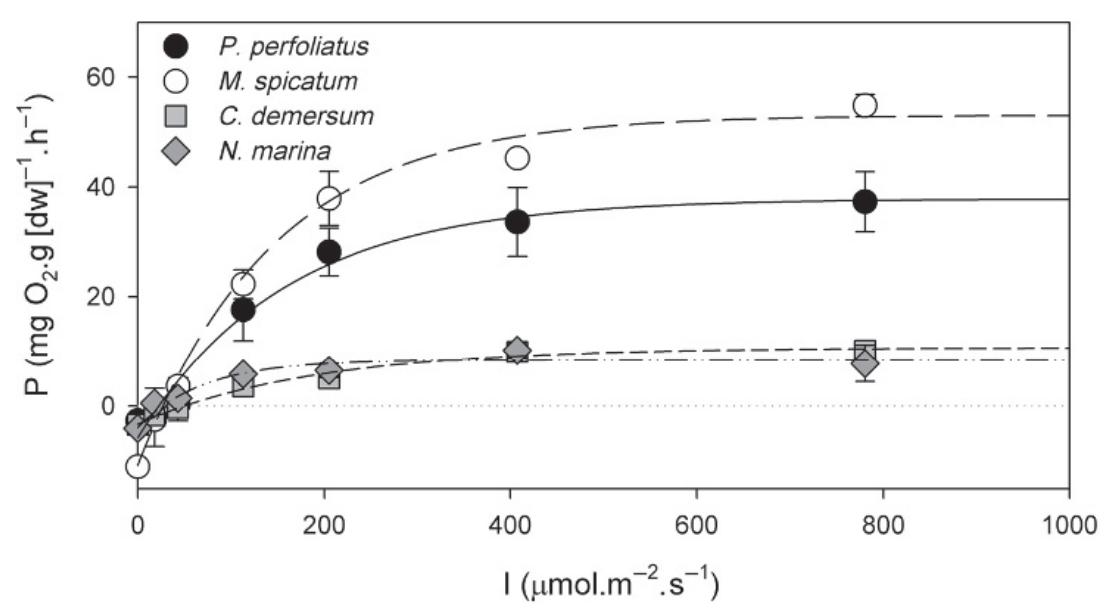

Fig. 6. Responses of photosynthetic rate in submerged macrophytes to different light intensities measured by the given incubation system. Each symbol represents mean $\pm \mathrm{SD}$ of three independent measurements from different plants.

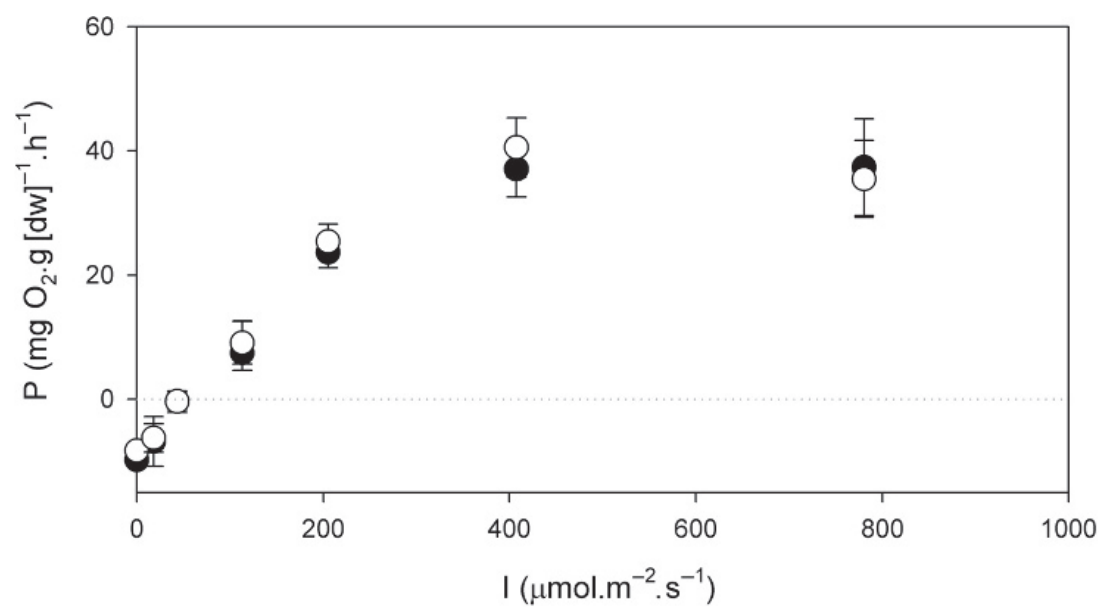

Fig. 7. Responses of photosynthetic rate of Potamogeton perfoliatus to different light intensities measured by the given incubation system. Black symbols $(\bullet)$ represents the first measurement, open symbols $(\bigcirc)$ are the one hour later repeated measurements. Each symbol represents mean $\pm \mathrm{SD}$ of three independent measurements from different plants. 
stability tests were repeated setting the temperature of the incubation system to 10 and $30{ }^{\circ} \mathrm{C}$. The experienced average temperature increase was $0.18 \pm 0.08$ and $0.22 \pm$ $0.08{ }^{\circ} \mathrm{C}$, respectively.

The usability of the equipment (incubation tank, light sources and cooling-heating bath) was assessed on the dominant rooted submerged macrophytes of lake Balaton, Potamogeton perfoliatus, Myriophyllum spicatum L., Ceratophyllum demersum $L$. and Najas marina $L$. Figure 6 shows the relationship between the photosynthetic activity of leaves (P) and irradiance (I), the so called light curve (P-I curve) of photosynthesis measured on all four species. At low light intensities due to mitochondrial respiration there was no gross $\mathrm{O}_{2}$ evolution. Small increase of irradiance accelerated the rate of photosynthetic activity proportionally, but at higher, saturating light intensities the P-I relation deviated from the linear relation and changed to exponential growth to maximum (Fig. 6). Over the saturation light intensity the rate of photosynthesis of rooting aquatic macrophytes didn't changed significantly reaching a plateau called the maximal rate of photosynthesis (Fig. 6).

To the data of $\mathrm{O}_{2}$ evolution obtained from our measurements curves were fitted using the exponential saturation model according Platt et al. (1980) $\left(\mathrm{P}=\mathrm{P}_{\mathrm{s}} \times\right.$ $\left.\left(1-\mathrm{e}^{-\alpha \cdot \mathrm{I} / \mathrm{Ps}}\right) \times \mathrm{e}^{-\beta \cdot \mathrm{I} / \mathrm{Ps}}\right)$. The $\mathrm{R}^{2}$ of the fitted equation model was between 0.948 and 0.997 , that is nearly all variability in results of photosynthetic oxygen evolution obtained using this system could be explained by the relation of photosynthesis to inherent light intensity (Fig. 6).

To test the repeatability of the system we remeasured light response of photosynthesis with the same plant material and same incubation water. Following the first measurement (Fig. 7, closed symbols) the plants were kept in darkness for $30 \mathrm{~min}$ prior the new measurements. The $\mathrm{O}_{2}$ saturation and $\mathrm{pH}$ of the incubation water was kept stable. The repeated measurement (open symbols) showed no statistically significant variation (Fig. 7).

\section{Conclusion}

The relatively simple structure of the incubation tank makes it an easy to put together and affordable device for study of photosynthesis responses of vast majority aquatic plants from phytoplankton up to the submerged macrophytes, although it could be used for any research that requires a gradient of light. Each cell of the incubation chamber was designed to fit Karlsruhe vials, but it can be used with any vials of less than $7 \mathrm{~cm}$ diameter or in the process of planning the sizes could be easily adjusted to any other parameters. Three out of four walls of an incubation cell were made of mirror glass and this resulted a more homogenous light environment for the studies, thus reducing the possibility of self-shading of plants.

The single transparent sidewall of each incubation cell was covered with $3 \mathrm{M}$ Scotchtint ${ }^{\mathrm{TM}}$ Sun Control RE50NEARL films. In this experiment the spectral profile of both a single and stratified film were recorded. The wavelengths were carefully compared with the closest to study the spectral uniformity of the film. Besides the slightly bigger (34\%) cut-off in the blue end (400-414 nm) of the PAR spectra the film had uniform spectral profile. Neither stratification, nor the prolonged exposure of the film to sun didn't change its spectral profile.

The experimental set consisting of the incubation tank, cooling-heating bath and fluorescent tubes maintained stable temperature for a relatively long period of time, thus making possible to compare the data obtained from different incubation cells. Assembling a light source consisting of several fluorescent lamps gives a sufficient light intensity to saturate the photosynthetic processes, while using a cooling-heating bath keeps the temperature variations within the incubation bath under $1 \%$.

Acknowledgements. The authors wish to thank the Hungarian National Office for Research and Technology for valuable financial support (3B022_04 BALÖKO).

\section{References}

Adams M.S., Titus J. and McCrackenM., 1974. Depth distribution of photosynthetic activity in a Myriophyllum spicatum community in Lake Wingra. Limnol. Oceanogr., 19, 377-389.

Asaeda T., Sultana M., Manatunge J. and Fujino T., 2004. The effect of epiphytic algae on the growth and production of Potamogeton perfoliatus L. in two light conditions. Environ. Exp. Bot., 52, 225-238.

Björkman O. and Demmig-Adams B., 1994. Regulation of Photosynthetic Light Energy Capture, Conversion, and Dissipation in Leaves of Higher Plants. In: Schulze E.D. and Caldwell M.M. (eds.), Ecophysiology of Photosynthesis, Ecological Studies, 100, Springer-Verlag, Berlin, 17 p.

Cedergreen N., Andersen L., Olesen C.F., Spliid H.H. and Streibig J.C., 2005. Does the effect of herbicide pulse exposure on aquatic plants depend on Kow or mode of action? Aquat Toxicol., 71, 261-271.

Eggert A., Van Hasselt P.R. and Breeman A.M., 2003. Chillinginduced photoinhibition in nine isolates of Valonia utricularis (Chlorophyta) from different climate regions. J. Plant Physiol., 160, 881-891.

Jones J.I., 2005. The metabolic cost of bicarbonate use in the submerged plant Elodea nuttallii. Aquat. Bot., 83, 371-381.

Kamara Sh. and Pflugmacher S., 2007. Phragmites australis and Quercus robur leaf extracts affect antioxidative system and photosynthesis of Ceratophyllum demersum. Ecotox. Environ. Safe., 67, 240-246.

Kirk J.T.O., 1996. Light and photosynthesis in aquatic ecosystems, Cambridge University Press, Cambridge, 44 p.

Lambert S.J., Thomas K.V. and Davy A.J., 2006. Assessment of the risk posed by the antifouling booster biocides Irgarol 1051 and diuron to freshwater macrophytes. Chemosphere, 63, 734-743.

Larcher W., 2003. Physiological Plant Ecology - Ecophysiology and Stress Physiology of Functional Groups, 4th edition, Springer-Verlag, Berlin, 107 p. 
Maberly S.C., 1983. The interdependence of photon irradiance and free carbon dioxide or bicarbonate concentration on the photosynthetic compensation points of freshwater plants. New Phytol., 93, 1-12.

Maberly S.C. and Madsen T.V., 1998. Affinity for $\mathrm{CO}_{2}$ in relation to the ability of freshwater macrophytes to use $\mathrm{HCO}_{3}^{-}$. Funct. Ecol., 12, 99-106.

Machova K., Elster J. and Adamec L., 2008. Xanthophyceaen assemblages during winter-spring flood: autecology and ecophysiology of Tribonema fonticolum and T. monochloron. Hydrobiologia, 600, 155-168.

Madsen T.V. and Sand-Jensen K., 1991. Photosynthetic carbon assimilation in aquatic plants. Aquat. Bot., 41, 5-40.

Madsen T.V., Maberly S.C. and Bowes G., 1996. Photosynthetic acclimation of submerged angiosperms to $\mathrm{CO}_{2}$ and $\mathrm{HCO}_{3}$. Aquat. Bot., 53, 15-30.

Nyström B., Van Slooten K.B., Bérard A., Grandjean D., Druart J.C. and Leboulanger C., 2002. Toxic effects of Irgarol 1051 on phytoplankton and macrophytes in Lake Geneva. Water Res., 36, 2020-2028.

Platt T.C., Gallegos L. and Harrison W.G., 1980. Photoinhibition of photosynthesis in natural assemblages of marine phytoplankton. J. Mar. Res., 38, 687-701.

Sand-Jensen K., 1977. Effect of epiphytes on eelgrass photosynthesis. Aquat. Bot., 3, 55-63.

Sand-Jensen K., 1989. Environmental variables and their effect on photosynthesis of aquatic plant communities. General features of aquatic photosynthesis. Aquat. Bot., $34,5-25$.
Sand-Jensen K. and Madsen T.V., 1991. Minimum light requirements of submerged freshwater macrophytes in laboratory growth experiments. J. Ecol., 79, 749-764.

Schwarz A.-M. and Howard-Williams C., 1993. Aquatic weedbed structure and photosynthesis in two New Zealand lakes. Aquat. Bot., 46, 263-281.

Shen H. and Song L., 2007. Comparative studies on physiological responses to phosphorus in two phenotypes of bloomforming Microcystis. Hydrobiologia, 592, 475-486.

Short F.T. and Neckles H.A., 1999. The effects of global climate change on seagrasses. Aquat. Bot., 63, 169-196.

Silva J., Santos R., Calleja M.L. and Duarte C.M., 2005. Submerged versus air-exposed intertidal macrophyte productivity: from physiological to community-level assessments. J. Exp. Mar. Biol. Ecol., 317, 87-95.

Van Duin E.H.S., Blom G., Los F.J., Maffione R., Zimmerman R., Cerco C.F., Dortch M. and Best E.P.H., 2001. Modeling underwater light climate in relation to sedimentation, resuspension, water quality and autotrophic growth. Hydrobiologia, 444, 25-42.

Vermaat J.E. and Verhagen F.C.A., 1996. Seasonal variation in the intertidal seagrass Zostera noltii Hornem.: coupling demographic and physiological patterns. Aquat. Bot., 52, 259-281.

Wang W. and Freemark K., 1995. The use of plants for environmental monitoring and assessment. Ecotox. Environ. Safe., 30, 289-301.

Wetzel R.G., 2001. Limnology: lake and river ecosystems, 3rd edition, Academic Press, London, 49 p. 